\section{Author's guidelines}

\section{Correspondence}

All editorial correspondence should be directed to the Editor, The Forestry Chronicle, 17 Elizabeth St. N., Richmond Hill, Ontario, L4C 4N4.

\section{Editorial policy}

The Forestry Chronicle is published by the Canadian Institute of Forestry/Institut Forestier du $\mathrm{Ca}$ nada to stimulate professional thought and discussion on the broad spectrum of Canadian forest land use. It is a forum for the expression of views and presentation of articles aimed at understanding and improving the management of this national resource. As such it provides common ground for dialogue between management, research, government, industry and education.

Articles up to 4,000 words (in French or English), points of view, discussion or comment on timely events, letters and reviews of books or other communications media will be considered for publication. Normally, only manuscripts that have not been published elsewhere will be considered. Publication does not imply endorsement of the author's view. The author is responsible for the accuracy of alf data and statements. All major and technical articles are reviewed by one or more referees.

At the discretion of the Editor, a pseudonym may be used if there are reasons why the author's name should not be divulged, but the latter must be included with the original submission. The Editor is not responsible for the loss of any manuscript, though care will be taken to avoid this event. The Editor reserves the right to edit manuscripts.

There is a charge of $\$ 40$ per page for technical articles based on research and undertaken by an institution or funded by grants. No individual is expected to pay this charge.

Galiey proofs of major articles are sent to authors for checking. They will also receive 10 free reprints; additional ones may be ordered at that time.

\section{The manuscript}

The following guidelines apply primarily to major articles and technical material but should also be consulted for any submission. Papers submitted must be in final form; the original and at least one, but preferably 2 , copies complete with illustrations are required.

Style and form. Write for the general readership; avoid specialized jargon. Seek a wide audience by simple but lively presentation. Use the active voice and first person wherever appropriate. Avoid long or complex tables and detailed graphical presentations. Keep references pertinent and to a minimum.

Examine current issues of The Forestry Chronicle for format. Use of metric equivalents with English units or conversion factors is encouraged. Spelling should follow Webster's Third International dictionary. Use Native Trees of Canada for tree names.
For technical articles, the Council of Biology Editors Style Manual (third edition) provides useful guidelines on form and style.

Typescript. Type all the manuscript (including references, footnotes, tables, etc.) double-spaced on white paper $8 \frac{1}{2} \times 11$ inches, leaving ample margins. This facilitates review and copy marking for the printer. (Use of paper with numbered lines also aids the review process.)

Type primary headings on a separate line flush with the left margin. Type secondary headings on the same line as the opening sentence of a paragraph. Underline words to be set in italics. Do not type words in capitals unless they are to appear as such (e.g. authors' names in the reference list).

On the first page, type the title, authors' names, authors' affiliations, and any relevant footnotes. The title and abstract, when required, should appear on the second page. The order for the rest of the manuscript is: text, references, tables, figure captions, figures. Number all pages consecutively.

Tities. Titles should be short and interesting but contain keywords to aid readers and abstracting services.

Abstract. An abstract is required for major articles and should not contain more than 250 words. All abstracts will be translated into French or English when this has not been done by the author.

References. Literature citations in the text should be by the author-date system or, where referencing interferes with readability, by superscript numbers. Check all references with the original article where possible, and type them, alphabetically and doublespaced, at the end of the text in the form used in current issues of the Chronicle. Names of publications should be abbreviated according to the American National Standards Institute list of abbreviations. If citation in the text is by number, include this number with the reference.

Tables. Number tables consecutively with arabic numerals and cite in text. Keep the title, column headings and descriptive matter short, simple and explicit. Use superscript letters for footnotes to tables. Place horizontal lines at the top and bottom of the table (see examples in the Chronicle) and do not use vertical rules.

Illustrations. Except for certain circumstances, all illustrations are designated as figures, numbered consecutively and keyed to the text. Do not send any illustration material larger than $8 \frac{1}{2} \times 11$ inches. Illustrations will be reduced to $2 \frac{1}{4}, 3 \frac{1}{4}, 4 \frac{1}{4}$ or $61 / 2$ inches in width, therefore lines and lettering (Letraset preferred; do not use a typewriter) shoud be clear and large enough to remain legible after reduction.

Photographs must be glossy, black and white prints with good contrast.

Identify all illustrations on the margin or back in soft pencil with the author's name and figure number. Type figure numbers and captions on a separate page; do not type or ink them on the illustration itself. 